\title{
Clinical Outcomes Associated with Use of Subcutaneous Sliding Scale Insulin Compared to Other Insulin Regimens in Hospitalized Patients
}

\author{
Lama S. Alfehaid ${ }^{*}$, Abdulmalik S. Alotaibi ${ }^{2}$, Ahmed S. Alanazi ${ }^{3}$, Rami T. Bustami ${ }^{4}$, \\ Razan El Melik ${ }^{5}$
}

${ }^{1}$ College of Pharmacy, King Saud Bin Abdulaziz University for Health Sciences, Riyadh, Saudi Arabia

${ }^{2}$ King Abdulaziz Medical City, National Guard Health Affairs, Riyadh, Saudi Arabia

${ }^{3}$ King Fahad Medical City, Riyadh, Saudi Arabia

${ }^{4}$ Alfaisal University, Riyadh, Saudi Arabia

${ }^{5}$ Mayo Clinic, Rochester, MN, USA

Email: ^fehaidl@ksau-hs.edu.sa

How to cite this paper: Alfehaid, L.S., Alotaibi, A.S., Alanazi, A.S., Bustami, R.T. and El Melik, R. (2018) Clinical Outcomes Associated with Use of Subcutaneous Sliding Scale Insulin Compared to Other Insulin Regimens in Hospitalized Patients. International Journal of Clinical Medicine, 9, 260-269.

https://doi.org/10.4236/ijcm.2018.94023

Received: March 16, 2018

Accepted: April 24, 2018

Published: April 27, 2018

Copyright $\odot 2018$ by authors and Scientific Research Publishing Inc. This work is licensed under the Creative Commons Attribution International License (CC BY 4.0).

http://creativecommons.org/licenses/by/4.0/

(c) (i) Open Access

\begin{abstract}
Background: Hyperglycemia in hospitalized patients is managed through one of the following approaches: sliding scale insulin (SSI) alone; SSI plus long-acting insulin and basal-bolus insulin (BBI). The optimal insulin treatment regimen is still debated. Objectives. To evaluate the clinical outcomes associated with the use of SSI compared to other regimens. Setting. The general medical wards in King Abdulaziz Medical City, Riyadh, Saudi Arabia. Methods. Medical charts for adult patients admitted between October 2014-December 2015 with type 2 diabetes or uncontrolled hyperglycemia with insulin treatment were reviewed. Data from capillary blood glucose were measured daily for the first 5 days of hospitalization and recorded. Demographics and blood glucose levels were compared by group using one-way ANOVA or Chi-square test. The number of hyperglycemic/hypoglycemic episodes was analyzed using the Kruskal-Wallis test. Results: A total of 240 patients were included. The three insulin regimen groups were not statistically different in terms of the number of days with episodes of hyper- or hypoglycemia $(p>0.05)$. However, a significantly bigger change from baseline (improvement) in random blood glucose (RBG) levels was observed in BBI and SSI plus glargine patients compared to SSI $(\mathrm{p}=0.014)$. Conclusion: Our study showed no significant difference in the number of days with episodes of hyper- or hypoglycemia for SSI vs. other insulin regimens. However, SSI patients had less improvement in their RBG levels compared to other insulin regimen
\end{abstract}


groups. Further studies with a larger sample size are needed to confirm these findings.

\section{Keywords}

Subcutaneous Sliding Scale Insulin, Hyperglycemia, Hospitalized Patients

\section{Introduction}

Diabetes is considered one of the most common leading causes of death. The epidemiologic data indicate that 347 million people worldwide have diabetes [1], whereas in Saudi Arabia the prevalence of diabetes is 34.1\% in males and $27.6 \%$ in females [2]. The most common form of diabetes is type 2 diabetes which represents about $90 \%$ - $95 \%$ of diabetic patients and is associated with obesity, older age, physical inactivity and family history [3]. Type 2 diabetes can be defined as an impaired utilization or insufficient amount of insulin that is produced by the pancreas which progresses slowly over time. Uncontrolled diabetes in majority of hospitalized patients is associated with increased risk of morbidity and mortality, increased the length of hospital stay and re-hospitalization rate [4] [5] [6].

The American Diabetes Association and the American College of Endocrinology recommend that glucose levels of all patients admitted to non-critical-care units should be maintained below $180 \mathrm{mg} / \mathrm{dL}$ (10.0 mmol/L) [7] [8]. Currently, hyperglycemia in hospitalized patients is managed through one of the following approaches of three approaches: sliding scale insulin (SSI) alone; every 6 hours as needed, SSI plus long-acting insulin (glargine) and basal-bolus insulin (BBI); (glargine once daily plus lispro insulin before meals). SSI has been used as the standard practice for diabetic patients since 1934 [9]. SSI is defined as the progressive increase in rapid or short-acting insulin in addition to scheduled insulin doses in order to maintain blood glucose levels within the desired targets. However, the use of SSI is not optimal due to the poor glycemic control it provides.

Recent randomized clinical trials showed that the use of BBI proved to be more effective than SSI in terms of achieving the desired blood glucose levels in hospitalized patients with type 2 diabetes [10] [11]. BBI treatment has been also shown to reduce morbidity in patients undergoing surgery [12]. BBI is based on giving long-acting insulin to maintain consistent blood glucose levels during fasting periods while taking into consideration the use of short-acting insulin injections to prevent potential increases in blood glucose levels caused by meals [13]. SSI plus long-acting insulin (glargine insulin) is based on a tight control of blood glucose levels throughout the day. SSI is not considered an ideal approach for controlling hyperglycemia due to a number of disadvantages it has; SSI does not take into consideration the requirements of basal insulin to prevent inter-meal and nocturnal hyperglycemia, or patient history concerning the use of 
insulin (resistance-sensitivity), diet or other characteristics. Furthermore, while SSI is used for treating hyperglycemia, it does not prevent hyperglycemia from occurring in the future, so it is not a proactive approach but rather reactive [14].

The assessment of glycemic control while using SSI is not regularly done. That is, diabetic patients do not get an immediate intervention from the health care provider unless blood glucose levels reach more than $396 \mathrm{mg} / \mathrm{dL}(22.2 \mathrm{mmol} / \mathrm{L})$ or less than $59.4 \mathrm{mg} / \mathrm{dL}(3.3 \mathrm{mmol} / \mathrm{L})[15]$.

\section{Aim of the Study}

Evaluate the treatment approach for acute hyperglycemia in hospitalized patients managed with SSI alone and compare its clinical outcomes with those using other insulin management approaches. Another objective of this study is to increase the awareness of medical teams in terms of the choice of the treatment approach for type 2 diabetes.

\section{Ethics Approval}

This retrospective observational study was approved by King Abdullah International Medical Research Center (KAIMRC), Riyadh, Saudi Arabia.

\section{Methods}

Medical charts were reviewed for all patients admitted to the general medical wards in King Abdulaziz Medical City, Riyadh, Saudi Arabia from October 2014 to December 2015. Inclusion criteria were:

1-patient aged more than 18,2-minimum length of stay of 5 days, 3-type 2 diabetes or uncontrolled hyperglycemia [random blood glucose (RBG) > 199.8 $\mathrm{mg} / \mathrm{dL}(11.1 \mathrm{mmol} / \mathrm{L})]$, and 4 -insulin treatment. Excluded Patients were those 1-with type 1 diabetes, 2-corticosteroid use, 3-critical illness, 4-pregnancy, 5-end-stage renal disease or hemodialysis $(\mathrm{CrCl}<15 \mathrm{~mL} / \mathrm{min})$, or 3-chronic illness (inactive patients or inpatients $>1$ month). Patients were identified and independently reviewed via QuadarMed CPR software by two of the investigators without direct patient contact. Collected data included: admission date, admission diagnosis, age, gender, hemoglobin A1C (\%), home and current antidiabetic medications, baseline and in-hospital capillary blood glucose levels [fasting blood glucose (FBG) and RBG], the total dose of insulin before and during admission and insulin type. Clinical circumstances surrounding the administration of insulin during the first 5 days of admission were described as hypoglycemia defined as a $\mathrm{FBG}<72 \mathrm{mg} / \mathrm{dL}(4 \mathrm{mmol} / \mathrm{L})$, hyperglycemia defined as $>180$ $\mathrm{mg} / \mathrm{dL}(10 \mathrm{mmol} / \mathrm{L})$ and severe hyperglycemia as $>360 \mathrm{mg} / \mathrm{dL}(20 \mathrm{mmol} / \mathrm{L})$. Insulin regimens were categorized into three groups: 1) SSI-administration of regular or rapid-acting insulin analogue every 4 to 6 hours without scheduled basal or prandial insulin, 2) SSI plus administration of long-acting insulin (glargine) and 3) BBI-glargine as basal insulin once daily and lispro as bolus insulin four-three times daily with meals. 


\section{Statistical Analysis}

Descriptive statistical analyses were initially performed for the study sample. Continuous variables were summarized using average and standard deviation, median and range. Proportions were used for categorical variables. To examine comparability of insulin regimen groups, baseline demographic and clinical factors were evaluated and compared in the three regimen groups. In-hospital blood glucose levels, as well as the number of days with hyperglycemia or hypoglycemia based on FBG and RBG, were evaluated and compared.

Categorical data were analyzed using Chi-square test. The distribution of all continuous data was examined. For continuous variables whose distributions approximate normality, one-way ANOVA was used for comparisons. When normality assumptions were not satisfied, the non-parametric Kruskal-Wallis test was utilized. Statistical significance was considered at $\mathrm{p}<0.05$. All statistical analyses were performed using SPSS 21.0 [Release 21.0.0.0].

To account for baseline blood glucose levels, multivariate linear regression analyses were employed to predict in-hospital FBG and RBG by insulin regimen group. Adjustments were made for age, gender, and blood glucose level at baseline.

\section{Results}

A total of 240 patients were included; 80 in SSI regimen group, 99 in SSI plus glargine regimen group and 61 in BBI regimen group. The average age was 69.1 years $(\mathrm{SD}=12.2)$, with $52 \%$ males. Overall, average baseline hemoglobin A1C was $9.3 \%$ ( $\mathrm{SD}=2.4)$; baseline RBG was $268.2 \mathrm{mg} / \mathrm{dL}(14.9 \mathrm{mmol} / \mathrm{L})(\mathrm{SD}=6.6)$ and baseline FBG was $175.5 \mathrm{mg} / \mathrm{dL}(9.75 \mathrm{mmol} / \mathrm{L})(\mathrm{SD}=4.3)$. Table 1 shows descriptive statistics and comparison of demographic and baseline factors in the three insulin regimen groups. The three groups were significantly different in terms of baseline RBG (average \pm SD: $232.2(12.9 \pm 6.7)$ for SSI, $279(15.5 \pm 6.3)$ for SSI plus glargine and $298.8(16.6 \pm 6.4)$ for BBI; $(\mathrm{p}=0.001)$. Baseline FBG was also significantly different in the three groups $153(8.5 \pm 3.4)$ for SSI, 189 $(10.5 \pm 4.3)$ for SSI plus glargine and $172.8(9.6 \pm 4.9)$ for BBI; $\mathrm{p}=0.028)$. The SSI group patients were significantly younger than other insulin group regimens ( $\mathrm{p}=0.014)$, while hemoglobin A1C was not statistically different in the three groups $(p>0.05)$. While a significantly bigger change from baseline (improvement) in RBG levels was observed in the BBI and SSI plus glargine patients compared to SSI ( $p=0.014$ ) (Table 1 ), there were no significant differences between the three groups in terms of number of hyperglycemic days based on FBG (median days was 3.0 for all groups; $\mathrm{p}=0.41$ ) or RBG (median days was 3.0 for both SSI and BBI and 4 days for SSI plus glargine; $\mathrm{p}=0.20$ ) (Table 2). Also, there were no significant differences between the three groups in terms of the number of hypoglycemic days based on FBG (median days was 0 for all groups, with a range of $2-4$ days; $\mathrm{p}=0.88$ ) (Table 3 ). The distribution of average RBG by regimen group over the 5 days of hospitalization is shown in the 
Table 1. Descriptive statistics for demographic and baseline data and follow-up by insulin type group. Total number of subjects $=240$.

\begin{tabular}{|c|c|c|c|c|}
\hline Factor & $\begin{array}{c}\text { SSI } \\
(\mathrm{N}=80,33.3 \%)\end{array}$ & $\begin{array}{c}\text { SSI + Glargine } \\
(\mathrm{N}=99,41.3 \%)\end{array}$ & $\begin{array}{c}\text { BBI } \\
(\mathrm{N}=61,25.4 \%)\end{array}$ & $\underset{*}{\mathrm{p} \text {-value }}$ \\
\hline \multicolumn{5}{|l|}{ Demographics \& baseline } \\
\hline Gender n (\%)Female & $32(40 \%)$ & $49(50 \%)$ & $34(51 \%)$ & \multirow{2}{*}{0.17} \\
\hline Male & $48(60 \%)$ & $50(51 \%)$ & $27(44 \%)$ & \\
\hline Age (years) Mean \pm SD & $60.1 \pm 11.7$ & $71.2 \pm 12.9$ & $67.1 \pm 11.3$ & \multirow{2}{*}{0.014} \\
\hline Median (range) & $70(35-92)$ & $74(36-96)$ & $67(43-95)$ & \\
\hline Hgb A1C (\%) Mean \pm SD & $8.8 \pm 2.4$ & $9.5 \pm 2.6$ & $9.7 \pm 2.0$ & \multirow{2}{*}{0.065} \\
\hline Median (range) & $8.2(5.5-15.3)$ & $8.9(5.2-15.9)$ & $9.7(6.2-15.3)$ & \\
\hline Random Blood Glucose(mmol/l) & $12.9 \pm 6.7$ & $15.5 \pm 6.3$ & $16.6 \pm 6.4$ & \multirow{3}{*}{0.001} \\
\hline Mean \pm SD & & & & \\
\hline Median (range) & $11(1.1-33.3)$ & $15.7(3.6-44.4)$ & $15.7(4.2-29.7)$ & \\
\hline Fasting Blood Glucose (mmol/l) & $8.5 \pm 3.4$ & $10.5 \pm 4.3$ & $9.6 \pm 4.9$ & \multirow{3}{*}{0.028} \\
\hline Mean \pm SD & & & & \\
\hline Median (range) & $7.9(2.7-17.8)$ & $9.7(3.2-21.6)$ & $8.2(3.1-23.8)$ & \\
\hline \multicolumn{5}{|l|}{ Follow Up } \\
\hline Random Blood Glucose (mmol/l) & $10.9 \pm 3.0$ & $12.0 \pm 3.0$ & $11.9 \pm 2.8$ & \multirow{3}{*}{0.025} \\
\hline Mean \pm SD & & & & \\
\hline Median (range) & $10.4(6.1-18.0)$ & $12.2(5.8-18.6)$ & $11.6(6.3-17.6)$ & \\
\hline Fasting Blood Glucose (mmol/l) & $8.7 \pm 2.5$ & $9.6 \pm 3.0$ & $9.2 \pm 2.8$ & \multirow{3}{*}{0.16} \\
\hline Mean \pm SD & & & & \\
\hline Median (range) & $8.2(4.2-16.4)$ & $9.4(4.9-20.1)$ & $8.8(3.3-16.1)$ & \\
\hline Change in Random Blood & $-1.8 \pm 5.3$ & $-3.3 \pm 5.8$ & $-4.5 \pm 5.5$ & \multirow{3}{*}{0.014} \\
\hline Glucose ${ }^{9}$ Mean \pm SD & & & & \\
\hline Median (range) & $-0.9(-18.4-9.3)$ & $-3.1(-32.0-7.5)$ & $-3.9(-15.9-10.0)$ & \\
\hline Change in Fasting Blood & $-0.3 \pm 2.6$ & $-1.0 \pm 3.7$ & $-0.7 \pm 3.7$ & \multirow{3}{*}{0.72} \\
\hline Glucose Mean \pm SD & & & & \\
\hline Median (range) & $-0.3(-6.3-6.5)$ & $-0.5(-10.7-6.8)$ & $0.01(-8.6-6.6)$ & \\
\hline
\end{tabular}

*Based on one-way ANOVA or the Kruskal-Wallis test for continuous variables and the Chi-square test for categorical variables. Average of (follow up - baseline) values.

Table 2. Descriptive statistics and comparison of in-hospital hyperglycemic days by insulin type group. Total number of subjects $=240$.

\begin{tabular}{|c|c|c|c|c|}
\hline Factor & $\begin{array}{c}\text { SSI } \\
(\mathrm{N}=80, \\
33.3 \%)\end{array}$ & $\begin{array}{c}\text { SSI + Glargine } \\
(\mathrm{N}=99, \\
41.3 \%)\end{array}$ & $\begin{array}{c}\text { BBI } \\
(\mathrm{N}=61, \\
25.4 \%)\end{array}$ & $\begin{array}{c}\text { p-value } \\
*\end{array}$ \\
\hline \multicolumn{5}{|l|}{ Fasting Blood Glucose } \\
\hline Hyperg. Days Mean \pm SD & $2.9 \pm 1.5$ & $3.2 \pm 1.5$ & $2.9 \pm 1.3$ & \multirow{2}{*}{0.41} \\
\hline Median (range) & $3(0-5)$ & $3(0-5)$ & $3(0-5)$ & \\
\hline \multicolumn{5}{|l|}{ Random Blood Glucose } \\
\hline Hyperg. Days Mean \pm SD & $2.8 \pm 1.9$ & $3.3 \pm 1.7$ & $3.2 \pm 1.7$ & \multirow{2}{*}{0.20} \\
\hline Median (range) & $3(0-5)$ & $4(0-5)$ & $3(0-5)$ & \\
\hline
\end{tabular}

${ }^{\star}$ Based on the Kruskal-Wallis test. Hypergylycemic: FBG $\geq 7 \mathrm{mmol} / \mathrm{l}, \mathrm{RBG} \geq 10 \mathrm{mmol} / \mathrm{l}$. 
Table 3. Descriptive statistics and comparison of in-hospital hypoglycemic days by insulin type group. Total number of subjects $=240$.

\begin{tabular}{|c|c|c|c|c|}
\hline Factor & $\begin{array}{c}\text { SSI } \\
(\mathrm{N}=80 \\
33.3 \%)\end{array}$ & $\begin{array}{c}\text { SSI + Glargine } \\
(\mathrm{N}=99 \\
41.3 \%)\end{array}$ & $\begin{array}{c}\text { BBI } \\
(\mathrm{N}=61, \\
25.4 \%)\end{array}$ & p-value ${ }^{*}$ \\
\hline \multicolumn{5}{|l|}{ Fasting Blood Glucose } \\
\hline Hypog. Days Mean \pm SD & $0.12 \pm 0.4$ & $0.11 \pm 0.4$ & $0.15 \pm 0.6$ & \multirow{2}{*}{0.88} \\
\hline Median (range) & $0(0-2)$ & $0(0-3)$ & $0(0-4)$ & \\
\hline
\end{tabular}

*Based on the kruskal-wallis test. Hypogylycemic: $\mathrm{FBG}<4 \mathrm{mmol} / \mathrm{l}$.

Box-and-Whisker plots in Figure 1. The boxes show the 25th, 50th (median) and 75th percentiles and whiskers show the minimum and maximum levels that are not outliers or extreme values. The figure demonstrates a significant difference between the three groups in terms of in-hospital RBG levels $(p=0.025)$. However, no significant differences were found between groups in terms of in-hospital FBG (not shown).

\section{Discussion}

This study was conducted to compare three insulin regimen approaches in the hospital; SSI, SSI plus glargine, and BBI. This study demonstrates that there was no significant difference in the number of days with episodes of hyper- or hypoglycemia associated with the use of SSI compared to other two insulin regimen approaches used for prevention or treatment of acute hyperglycemia in general medical hospitalized patients. While we observed a significant difference between the groups in terms of in-hospital RBG levels with higher levels detected among patients treated with SSI plus glargine or BBI, our study showed no significant differences between the three insulin treatment groups in terms of hyperglycemic days. These results differ from previous observational studies in diabetic hospitalized patients, where blood glucose values were significantly higher in patients treated with SSI compared to those treated with either long-acting insulin regimens or combination of SSI and long-acting insulin [16] [17]. Also, our findings contradict a recently published randomized control trial which demonstrated that SSI insulin was associated with hypoglycemia with blood glucose lower than $72 \mathrm{mg} / \mathrm{dL}(4 \mathrm{mmol} / \mathrm{L})$ more than BBI, while no association was found with severe hypoglycemia indicated by blood glucose levels lower than $45 \mathrm{mg} / \mathrm{dL}$ ( $2.5 \mathrm{mmol} / \mathrm{L})$ [18]. In contrast, our findings were similar to those obtained in a study comparing SSI with BBI among non-critically ill patients where no significant difference was found between the two insulin regimens in terms of the incidence of moderate or severe hypoglycemia [19].

However, it is important to recognize that baseline blood glucose measures for SSI patients were significantly lower compared to those treated with BBI or SSI plus glargine. This may be related to the preference of ordering the SSI regimen for those patients when hypoglycemia is a major concern. Also, results from a prospective randomized control trial comparing the use of BBI with SSI alone 


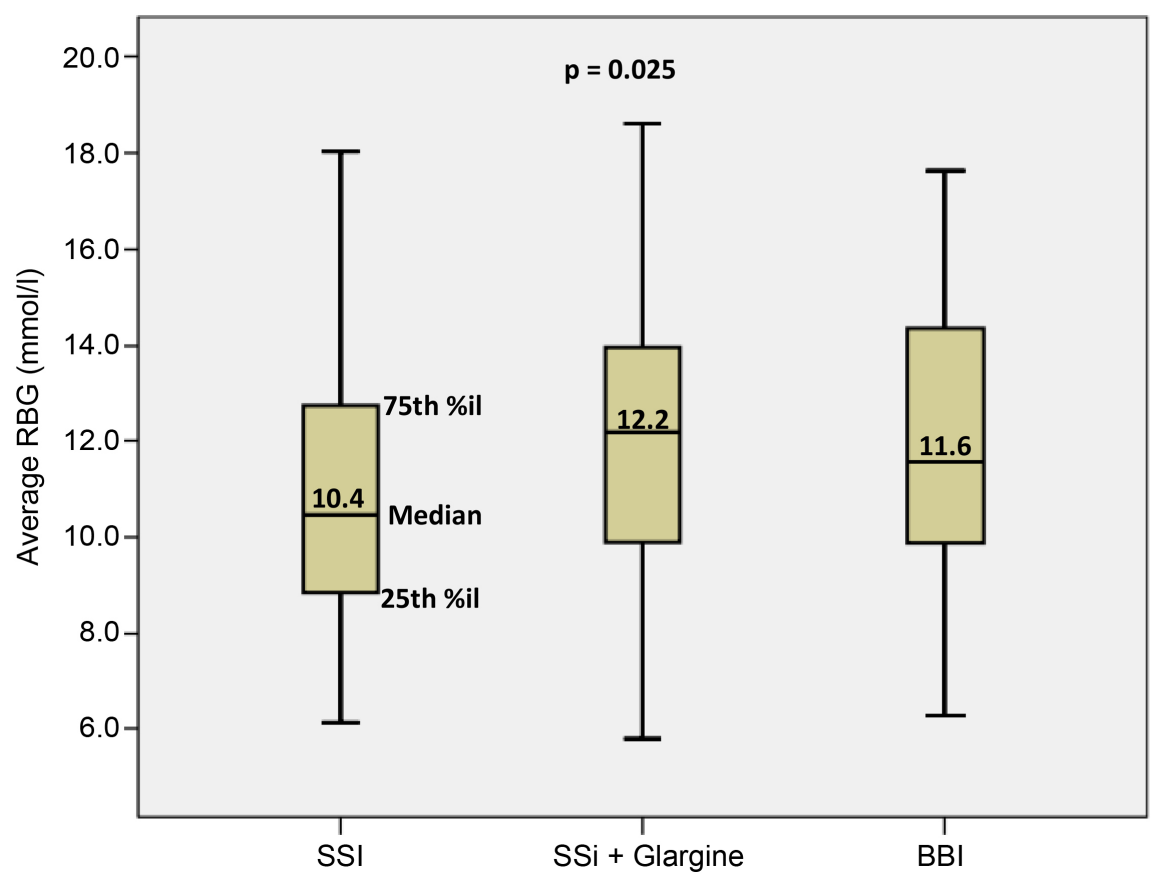

Figure 1. Box-and-whisker plots for average in-hospital RBG levels by insulin regimen group. Total number of subjects $=240$.

showed that the BBI group had greater improvement in blood glucose control compared to SSI [20]. Nevertheless, the data revealed no difference in the number of days with hypoglycemia in the three groups. This result contrasts other previous studies, where tight glycemic control patients experienced the higher rate of hypoglycemia compared to those on the SSI regimen [20] [21]. Most of these studies focused on critically ill patients, and in our study, several patients had received nothing by mouth which could be a possible explanation for this result as the SSI practice involve administration of short-acting insulin regardless of whether the patient is receiving food or not. A similar retrospective study conducted on non-critically ill patients found that tight glycemic control patients are more likely to have their blood glucose levels at goal with the lower risk of hypoglycemia compared with the patient treated with SSI alone [16]. Also, SSI patients are more likely to have their blood glucose levels checked using blood glucose meters compared to other groups. This is in addition to numerous insulin injections, thus increasing discomfort for those patients and potentially increasing the risk of advanced micro- or macrovascular complications that may negatively impact the quality of life particularly for elderly and long-term hospitalized patients.

This study has number of limitations. First, the design is retrospective where the choice of treatment was purely at the discretion of the treating clinician, which may have generated bias. Secondly, our study suffers from a relatively small sample size limiting our ability to detect other possible significant predictors of blood glucose control. Therefore, our results may not be generalizable to all diabetic hospitalized patients. Furthermore, this study did not examine the 
impact of glycemic control on patient outcomes. Patients were followed for only 5 days, which may not be enough time to show the complete effect of glycemic control using insulin.

Despite these limitations, our study has several strengths. First, it was aimed at evaluating and comparing the SSI approach with other insulin regimens that are commonly used as interventions in prevention or treatment of acute hyperglycemia in hospitalized patients. Only a few studies have focused on comparing these 3 approaches in non-critically ill patients. Additionally, we have used the average as a summary of all available blood glucose measures instead of arbitrarily selecting measures to assess the difference in blood glucose control between groups thus minimizing the potential bias from neglecting important values that may impact outcomes. Finally, the study population was well-defined with rigorous inclusion criteria. In fact, majority of data were prospectively collected during the study duration and for a long observation period which adds to the quality of recorded data.

\section{Conclusion}

While we found a significant difference between insulin regimen groups in terms of in-hospital RBG levels, no statistically significant difference was observed in the number of days with episodes of hyper- or hypoglycemia associated with the use of SSI versus other insulin regimen groups. Further studies using a larger sample size are needed to confirm these findings.

\section{Acknowledgements}

We would like to show our appreciation to our colleagues from College of Pharmacy at King Saud bin Abdulaziz University for Health Sciences, Prof. Salahdein Aburuz and Mr. Wesam Ismail for their valuable comments on an earlier version of the manuscript, which greatly improved it.

\section{Funding}

This research did not receive any specific grant from funding agencies in the public, commercial, or not-for-profit sectors.

\section{Conflict of Interests}

The authors declare that they have no conflict of interests

\section{References}

[1] Danaei, G., Finucane, M., Lu, Y., Singh, G., et al. (2011) National, Regional, and Global Trends in Fasting Plasma Glucose and Diabetes Prevalence since 1980: Systematic Analysis of Health Examination Surveys and Epidemiological Studies with 370 Country-Years and 2.7 Million Participants. The Lancet, 378, 31-40. https://doi.org/10.1016/S0140-6736(11)60679-X

[2] Aljabri, K., Bokhari, S. and Alqurashi, K. (2011) Prevalence of Diabetes Mellitus in a Saudi Community. Annals of Saudi Medicine, 31, 19-23. 
https://doi.org/10.4103/0256-4947.75773

[3] Diabetes Successes and Opportunities for Population-Based Prevention and Control at a Glance. CDC National Center for Chronic Disease Prevention and Health Promotion. 2011.

https://www.cdc.gov/chronicdisease/resources/publications/aag/diabetes.htm

[4] Leite, S., Locatelli, S., Niece, S., Oliveira, A., Tockus, D. and Tosin, T. (2010) Impact of Hyperglycemia on Morbidity and Mortality, Length of Hospitalization and Rates of Re-Hospitalization in a General Hospital Setting in Brazil. Diabetology \& Metabolic Syndrome, 2, 49. https://doi.org/10.1186/1758-5996-2-49

[5] Kim, S., Kim, B., Ha, E., Moon, M. and Park, S. (2010) Effect of Hyperglycemia on Mortality Rates in Critically Ill Children. Korean Journal of Pediatrics, 53, 323-328. https://doi.org/10.3345/kjp.2010.53.3.323

[6] Falciglia, M. (2010) Hyperglycemia-Related Mortality in Critically Ill Patients Varies with Admission Diagnosis. Critical Care Medicine, 38, 1388-1389. https://doi.org/10.1097/CCM.0b013e3181d8be4b

[7] Clement, S., Braithwaite, S., Magee, M., et al. (2004) Management of Diabetes and Hyperglycemia in Hospitals. Diabetes Care, 27, 553-591.

https://doi.org/10.2337/diacare.27.2.553

[8] Garber, A.J., Moghissi, E.S., Bransome, E.D., et al. (2004) American College of Endocrinology position statement on Inpatient Diabetes and Metabolic Control. Endocrine Practice, 10, 4-9. https://doi.org/10.4158/EP.10.S2.4

[9] Joslin, E. (1919) A Diabetic Manual for the Mutual Use of Doctor and Patient. 2nd Edition, Lea \&Febiger, Philadelphia and New York.

[10] Umpierrez, G., Smiley, D., Zisman, A., et al. (2007) Randomized Study of Basal-Bolus Insulin Therapy in the Inpatient Management of Patients with Type 2 Diabetes (RABBIT 2 Trial). Diabetes Care, 30, 2181-2186. https://doi.org/10.2337/dc07-0295

[11] Umpierrez, G.E., Smiley, D., Jacobs, S., et al. (2011) Randomized Study of Basal-Bolus Insulin Therapy in The Inpatient Management of Patients with Type Two Diabetes Undergoing General Surgery (RABBIT 2 Surgery). Diabetes Care, 34, 256-261. https://doi.org/10.2337/dc10-1407

[12] Michota, F. (2007) What Are the Disadvantages of Sliding-Scale Insulin? The Journal of Hospital Medicine, 2, 20-22. https://doi.org/10.1002/jhm.183

[13] Umpierrez, G.E., Palacio, A. and Smiley, D. (2007) Sliding Scale Insulin Use: Myth or Insanity? The American Journal of Medicine, 120, 563-567. https://doi.org/10.1016/j.amjmed.2006.05.070

[14] Browning, L.A. and Dumo, P. (2004) Sliding-Scale Insulin: An Antiquated Approach to Glycemic Control in Hospitalized Patients. American Journal of Health-System Pharmacy, 61, 1611-1614.

[15] Hirsch, I.B. (2009) Sliding Scale Insulin-Time to Stop Sliding. JAMA, 301, 213-214.

[16] Patel, G.W., Roderman, N., Lee, K.A., et al. (2009) Sliding Scale versus Tight Glycemic Control in the Non-Critically Ill at a Community Hospital. Annals of Pharmacotherapy, 43, 1774-1780. https://doi.org/10.1345/aph.1M331

[17] Dharmarajan, M.D., Zambrano, A., et al. (2016) Sliding Scale Insulin vs Basal-Bolus Insulin Therapy in Long-Term Care: A 21-Day Randomized Controlled Trial Comparing Efficacy, Safety and Feasibility. JAMDA, 17, 206-213.

[18] Valgardson, J., Merino, M., Redgrave, J., Hudson, J. and Hudson, M. (2015) Effectiveness of Inpatient Insulin Order Sets Using Human Insulins in Noncritically Ill 
Patients in a Rural Hospital. Endocrine Practice, 21, 794-806. https://doi.org/10.4158/EP14153.OR

[19] Akhtar, S.T., Mahmood, K., Naqvi, I.H. and Vaswani, A.S. (2014) Inpatient Management of Type2 Diabetes Mellitus: Does Choice of Insulin Regimen Really Matter? Pakistan Journal of Medical Sciences, 30, 895-898.

[20] Gearhart, J.G., Duncan, J.L., Replogic, W.H., Forbes, R.C. and Walley, E.J. (1994) Efficacy of Sliding-Scale Insulin Therapy: A Comparison with Prospective Regimens. The Family Practice Research Journal, 14, 313-322.

[21] Roberts, G.W., Aguilar-Loza, N., Esterman, A., Burt, M.G. and Stranks, S.N. (2012) Basal-Bolus Insulin versus Sliding-Scale Insulin for Inpatient Glycaemic Control: A Clinical Practice Comparison. The Medical Journal of Australia, 196, 266-269. https://doi.org/10.5694/mja11.10853 